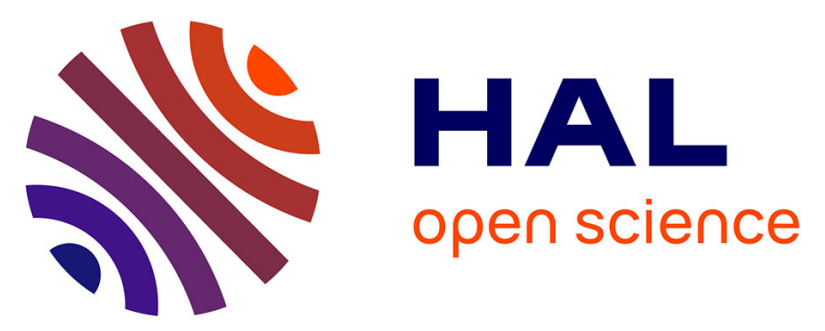

\title{
Ferroelectric and dielectric study of strontium tantalum based perovskite oxynitride films deposited by reactive rf magnetron sputtering
}

Claire Le Paven, Ratiba Benzerga, Anthony Ferri, Didier Fasquelle, Vincent Laur, Laurent Le Gendre, Florent Marlec, Franck Tessier, François Cheviré, Rachel Desfeux, et al.

\section{To cite this version:}

Claire Le Paven, Ratiba Benzerga, Anthony Ferri, Didier Fasquelle, Vincent Laur, et al.. Ferroelectric and dielectric study of strontium tantalum based perovskite oxynitride films deposited by reactive rf magnetron sputtering. Materials Research Bulletin, 2017, The 9th international conference on the Microwave Materials and Their Applications, 96 (Part 2), pp.126-132. 10.1016/j.materresbull.2016.11.030 . hal-01404863

\section{HAL Id: hal-01404863 https://hal.science/hal-01404863}

Submitted on 1 Dec 2016

HAL is a multi-disciplinary open access archive for the deposit and dissemination of scientific research documents, whether they are published or not. The documents may come from teaching and research institutions in France or abroad, or from public or private research centers.
L'archive ouverte pluridisciplinaire HAL, est destinée au dépôt et à la diffusion de documents scientifiques de niveau recherche, publiés ou non, émanant des établissements d'enseignement et de recherche français ou étrangers, des laboratoires publics ou privés. 
Ferroelectric and dielectric study of strontium tantalum based perovskite oxynitride films deposited by reactive rf magnetron sputtering

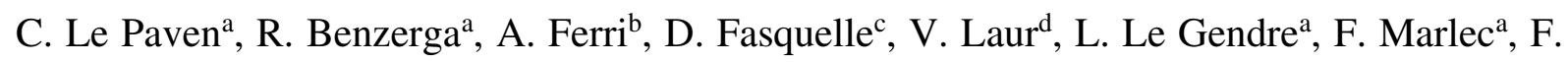

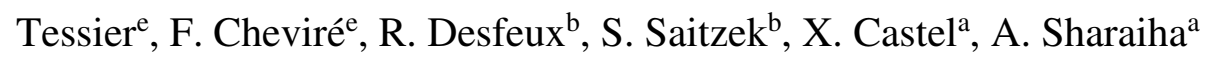

a Institut d'Electronique et de Télécommunications de Rennes (IETR), Equipe Matériaux Fonctionnels, IUT Saint-Brieuc, Université de Rennes 1, F-22000 Saint Brieuc, France.

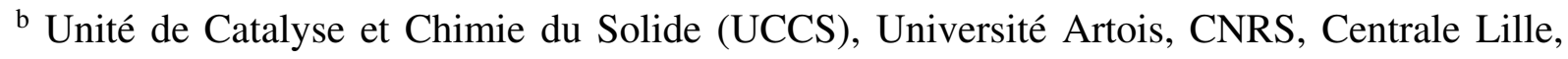
ENSCL, Université Lille, F-62300 Lens, France.

${ }^{c}$ Unité de Dynamique et Structure des Matériaux Moléculaires (UDSMM), Université du Littoral Côte d'Opale-Université de Lille 1, F-62100 Calais, France

${ }^{\mathrm{d}}$ Laboratoire des Sciences et Techniques de 1'Information, de la Communication et de la Connaissance (LABSTICC), Pôle Micro-ondes et Matériaux, Université de Bretagne Occidentale, F-29 000 Brest, France

${ }^{\text {e } I n s t i t u t ~ d e s ~ S c i e n c e s ~ C h i m i q u e s ~ d e ~ R e n n e s ~(I S C R), ~ E q u i p e ~ V e r r e s ~ e t ~ C e ́ r a m i q u e s, ~ U n i v e r s i t e ́ ~}$ de Rennes 1, F-35000 Rennes, France. 


\section{Graphical abstract}
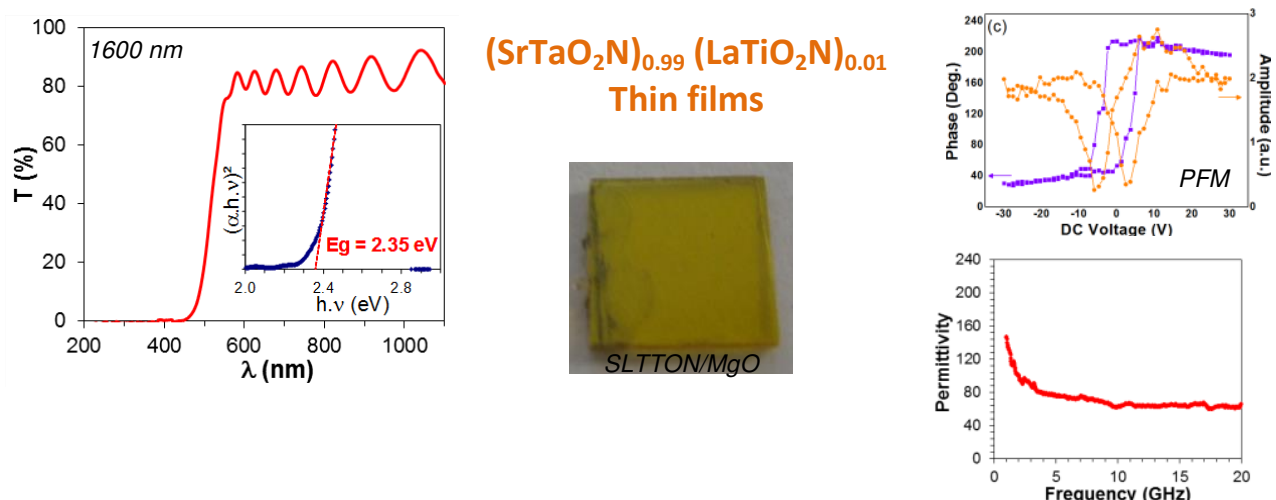


\title{
Highlights
}

- Oxynitride perovskite thin films were deposited by reactive sputtering.

- Films are textured or epitaxially grown on $\mathrm{MgO}$ and $\mathrm{Nb}-\mathrm{SrTiO}_{3}$ substrates.

- Local piezoelectric and ferroelectric behavior was highlighted by PFM.

- A $1600 \mathrm{~nm}$-thick film presents a permittivity of 175 at $10 \mathrm{kHz}$ and RT.

- Permittivity is around 65 in high frequency range.

\begin{abstract}
Strontium and tantalum based oxynitride perovskite thin films were deposited by reactive magnetron sputtering. Epitaxial films deposited on $\mathrm{Nb}_{-} \mathrm{SrTiO}_{3}$ substrates show smooth surfaces with roughness values from 1.5 to $3.6 \mathrm{~nm}$ for a thickness of films in the range 20 $1600 \mathrm{~nm}$. The samples are yellow with band gap values around $2.35 \mathrm{eV}$. Piezo-force microscopy characterization pointed out the local piezoelectric and ferroelectric behavior of the oxynitride perovskite films. In the low frequency range, the $1600 \mathrm{~nm}$-thick film exhibits a permittivity of 175 at $10 \mathrm{kHz}$, with dielectric losses of 0.055 . Permittivity is lowered in high frequencies with a value around 65 obtained on a $1520 \mathrm{~nm}$-thick film deposited on $\mathrm{MgO}$ substrate, which is textured with a preferential c-axis orientation. No accordability of the permittivity was highlighted at a macroscopic scale. The moderate crystallographic strain evidenced in the $20 \mathrm{~nm}$ thin film does not induce a high permittivity.
\end{abstract}

\section{Introduction}


The perovskite oxynitride compounds have received much attention in recent years due to their original properties compared to their oxide parents. For example, the decrease of the band-gap consecutive of the nitrogen substitution for oxygen in the perovskite structure leads to an absorption in the visible domain, with potential applications as pigments $[1,2]$ and visible photocatalysts, for instance, in overall water splitting reactions [3]. Moreover, high permittivities have been reported. For the $\mathrm{SrTaO}_{2} \mathrm{~N}$ compound, closest reported material for comparison with our results as explained hereafter, Kim et al. first reported a permittivity $\kappa=$ $2800 @ 1 \mathrm{MHz}, \mathrm{RT}$ on $55 \%$ dense ceramics [4]. Zhang et al. confirmed this trend with $\kappa=$ $10000 @ 1 \mathrm{MHz}, \mathrm{RT}$ on a 90\% dense ceramic post-annealed in ammonia [5]. Recently, Sun et al. reported $\kappa=355 @ 1 \mathrm{MHz}, \mathrm{RT}$ for a $84 \%$ dense pellet densified with $\mathrm{SrCO}_{3}$ and post annealed in ammonia [6]; no drastic change of permittivity was observed in the temperature range $20-160^{\circ} \mathrm{C}$. On thin films, data are dramatically scarce. Oka et al. reported a permittivity close to $2000 @ 10 \mathrm{kHz}, \mathrm{RT}$ for a 290 nm-thick epitaxial film [7]; no significant change was observed upon cooling the films down to $50 \mathrm{~K}$ and varying frequency from $20 \mathrm{~Hz}$ to $100 \mathrm{kHz}$. The high values of permittivity observed on perovskite oxynitrides are currently assigned to a possible local oxygen/nitrogen ordering with a cis-type configuration of the nitrogen atom in the $\mathrm{MO}_{4} \mathrm{~N}_{2}$ octaedra (M: transition metal, lanthanide) [8,9]. A local ferroelectric behavior has been demonstrated on $\mathrm{SrTaO}_{2} \mathrm{~N}$, as bulk [10] and thin films [7].

The aim of our research is to provide experimental data on the oxynitride perovskite compounds, especially on their dielectric and ferroelectric properties. Moreover, we are looking for high permittivity materials for integration in miniaturized/agile devices such as antennas. Given the great difficulty of densifying oxynitrides ceramics, our approach has turned to the synthesis of these compounds in the form of thin films, as reported in other studies [11,12]. We have conducted research on $\mathrm{LaTiO}_{2} \mathrm{~N}$ films deposited by reactive sputtering from oxynitride $\mathrm{LaTiO}_{2} \mathrm{~N}$ [13] and oxide $\mathrm{La}_{2} \mathrm{Ti}_{2} \mathrm{O}_{7}$ [14] targets. Recently, our 
interest has been focused on the deposition of films from the solid solution (1-x) $\mathrm{Sr}_{2} \mathrm{Ta}_{2} \mathrm{O}_{7}$, $\mathrm{xLa}_{2} \mathrm{Ti}_{2} \mathrm{O}_{7}$ [15]. The oxide precursors are both ferroelectric materials with Curie temperatures of $-107^{\circ} \mathrm{C}$ for $\mathrm{Sr}_{2} \mathrm{Ta}_{2} \mathrm{O}_{7}$ [16] and $1500^{\circ} \mathrm{C}$ for $\mathrm{La}_{2} \mathrm{Ti}_{2} \mathrm{O}_{7}$ [17]. According to the results of Nanamatsu [16], it is expected that the $\left.\left(\mathrm{Sr}_{0.99} \mathrm{La}_{0.01}\right)_{2}\left(\mathrm{Ta}_{0.99} \mathrm{Ti}_{0.01}\right)_{2} \mathrm{O}_{7}\right)$ oxide is ferroelectric with a Curie temperature close to room temperature. We have shown that in reactive $\mathrm{Ar}+\mathrm{O}_{2}$ $+\mathrm{N}_{2}$ plasmas, oxide films are obtained for plasmas containing dioxygen and dinitrogen whereas oxynitride $\left(\mathrm{Sr}_{0.99} \mathrm{La} 0.01\right)\left(\mathrm{Ta}_{0.99} \mathrm{Ti}_{0.01}\right) \mathrm{O}_{2} \mathrm{~N}$ (SLTTON) films are produced only in $\mathrm{Ar}+$ $\mathrm{N}_{2}$ plasmas, that is without $\mathrm{O}_{2}[18]$.

The purpose of the present contribution is to provide a complete dielectric and ferroelectric characterization of oxynitride SLTTON perovskite films. The first series of films is composed of oxynitride samples deposited on conducting $\mathrm{Nb}$-doped $\mathrm{SrTiO}_{3}$ substrates for the nanoscale Piezoelectric Force Microscopy (PFM) analysis and for the low frequency dielectric characterization using Metal Insulating Metal (MIM) structures. This series also concerns films with different thickness in order to evaluate the effect of a possible crystallographic strain on the dielectric properties of oxynitride films. The second series contains samples deposited on $\mathrm{MgO}$ substrates for the high frequency dielectric characterization, using metallic transmission lines and a resonant cavity.

\section{Materials and methods}

Film deposition was carried out using radio frequency (rf) reactive magnetron sputtering in a Plassys MP450S reactor using a homemade $\left(\mathrm{Sr}_{0.99}, \mathrm{La} 0.01\right)_{2}\left(\mathrm{Ta} 0.99, \mathrm{Ti}_{0.01}\right)_{2} \mathrm{O}_{7}$ (SLTTO) target. This one, $75 \mathrm{~mm}$ in diameter, was obtained by uniaxial compaction of SLTTO powder under $80 \mathrm{MPa}$. The oxide powder was synthetized by solid state chemical route from stoichiometric amounts of $\mathrm{SrCO}_{3}, \mathrm{Ta}_{2} \mathrm{O}_{5}, \mathrm{La}_{2} \mathrm{O}_{3}$ and $\mathrm{TiO}_{2}$ heated under air at 
$1400^{\circ} \mathrm{C}$ during $30 \mathrm{~h}$. X-ray diffraction (XRD) analysis confirms the crystallization of the powder according to a $\mathrm{Sr}_{2} \mathrm{Ta}_{2} \mathrm{O}_{7}$ analogue (see Supplementary Data 1).

For the sputtering deposition, the plasma gas mixture contained $92.3 \mathrm{vol} . \%$ of argon and $7.7 \mathrm{vol} . \%$ of dinitrogen, with a total pressure $\mathrm{p}_{\mathrm{T}}=40$ mTorr. The rf power was fixed at $\mathrm{P}_{\mathrm{rf}}$ $=90 \mathrm{~W}\left(2.04 \mathrm{~W} / \mathrm{cm}^{2}\right)$ with a target-substrate distance $\mathrm{d}=5 \mathrm{~cm}$. The substrate temperature was maintained at $\mathrm{Ts}_{\mathrm{s}}=750^{\circ} \mathrm{C}$. Before deposition, a pre-sputtering of the target was performed during 30 min under the reactive gas mixture. The films were cooled under the same gas mixture than deposition at $10^{\circ} / \mathrm{min}$; no post-annealing was performed. Films of the present study were deposited using the same sputtering conditions, except the duration of depositions in order to access different thickness of samples. Two series of SLTTON samples were prepared: a first one for the Piezo-force microscopy measurements and for the dielectric characterization in the low frequency range, a second one for the dielectric characterization in the high frequency range.

The first series contains three films with thickness $t=20 ; 300 ; 1600 \mathrm{~nm}$. There were deposited on conducting niobium doped (001) $\mathrm{Nb}: \mathrm{SrTiO}_{3}$ substrates, acting as bottom electrodes in the MIM structures. Twin films deposited on (001) $\mathrm{MgO}$ substrates have served for the UV-visible transmittance characterization of samples giving the band gap of materials, as well for the thickness measurement by scanning electronic microscopy (SEM). SLTTON films of the first series are named relatively to their thickness.

The second series contains two films of the same thickness $(1520 \mathrm{~nm})$ deposited on (001) $\mathrm{MgO}$ substrates for the high frequency dielectric characterization. SLTTON-Hf1 was measured as function of frequency using transmission lines, whereas SLTTON-Hf2 was used for the precise determination of the dielectric losses via a measurement at a fixed frequency in a resonant cavity. SLTTON-Hf2 is a special sample, divided in two parts as can be seen in 
Supplementary Data 2: a $10 \times 10 \mathrm{~mm}^{2}$ area made of the $\mathrm{MgO}$ substrate alone for an "unloaded" measure; a 10 x $10 \mathrm{~mm}^{2}$ area made of the SLTTON film on MgO for a "loaded" measure.

Thickness of layers was measured by SEM cross-sectional view using a JEOL 5440 SEM operating at $10 \mathrm{kV}$. Nanoscale experiments on films were conducted using a MFP-3D (Asylum Research) atomic force microscope (AFM) in contact mode under ambient conditions. Surface morphology was characterized by using $\mathrm{Pt} / \mathrm{Ir}$ coated silicon tips (Arrow CONTPt, NanoWorld).

X-ray $\theta-2 \theta$ and $\phi$ diffractograms were recorded using a Seifert XRD 3003 diffractometer with a copper anode $\left(\mathrm{Cu} \mathrm{K}_{\alpha 1}\right.$ radiation). UV-Visible transmittance spectra were collected by a Perkin-Elmer Lambda 20 spectrometer operating in the range [200-1100] nm. Assuming direct transitions, band-gap values were obtained using the relation:

$$
(\alpha h v)^{2}=\left(h v-E_{g}\right)
$$

where $h v$ is the photon energy. Hence plotting $(\alpha h v)^{2}$ as a function of $h v$, the extrapolation of the linear region at zero gives the value of $E_{g}[19]$. The error is estimated as $0.05 \mathrm{eV}$.

PFM measurements were performed with $\mathrm{Pt} / \mathrm{Ir}$ coated probes (PPP-EFM, NanoSensors) and stiff cantilevers $(k \sim 4 \mathrm{~N} / \mathrm{m})$ to minimize electrostatic contribution in the detected PFM signal. Dual AC resonance tracking (DART) mode of the PFM was employed in order to enhance the piezoelectric signal [20], while remnant piezoresponse loops, i.e. at zero DC bias field, were recorded to promote the electromechanical response. For these spectroscopic PFM measurements, the driving voltage was set to $1.5 \mathrm{~V}$ at the probe tip and the conductive substrate was grounded. 
Low frequency dielectric properties were measured at room temperature by a LCR meter (LCR-819 GWInstek) on MIM structures. The conducting substrate (Nb:SrTiO 3$)$ was used as bottom electrode, whereas $200 \mathrm{~nm}$ sputtered silver served as the top electrodes. A stabilized Keithley 2400 supply was used to provide DC electric fields in order to evaluate the variation of the permittivity of films as function of electric bias (i.e. agility of samples).

The extraction of the microwave properties of the oxynitrides films was done by using two different methods: transmission lines and a resonant cavity. The transmission line method consists in measuring the reflection $S_{11}$ and the transmission $S_{21}$ parameters of a charged coplanar line (silver line on the $\mathrm{MgO}$ substrate covered by the oxynitride dielectric film). Effective permittivity and losses of this multilayer structure are then determined. The intrinsic characteristics of the dielectric film are further extracted using the "conformal mapping method" developped by Carlsson and Gevorgian [21]. Measurements were made using a HP8510C network analyzer associated to a Signatone H100 probe station, from 1 to $20 \mathrm{GHz}$. Sputtering silver metallization $(2 \mu \mathrm{m} \mathrm{Ag}$ and $5 \mathrm{~nm} \mathrm{Ti}$ as adhesion layer) on the oxynitride/MgO bilayer followed by a standard photolithographic wet etching process $\left(\mathrm{HNO}_{3} / \mathrm{H}_{3} \mathrm{PO}_{4} / \mathrm{CH}_{3} \mathrm{COOH} / \mathrm{H}_{2} \mathrm{O}\right.$ solution for silver and $\mathrm{HF} / \mathrm{H}_{2} \mathrm{O}$ solution for $\mathrm{Ti}$ ) were used to define the metallic patterns of the transmission lines.

The cavity method proved to be appropriate to characterize thin dielectric films [22], giving very accurate values of the microwave dielectric properties of materials [23]. Here, it was employed to extract precise values of dielectric losses. However, on the contrary to transmission line methods, it is limited to a single frequency which depends on the size of the cavity. In this study, we used a cavity constituted by a 5-cm long WR-90 waveguide coupled by circular apertures. A non-radiating slot, placed in the middle of the waveguide section, allows inserting the material under test. A low perturbation approach is used to extract the dielectric properties of the thin film under study. At first, an $\mathrm{MgO}$ substrate is inserted in the 
cavity; this "unloaded" measurement will constitute the reference. Then, a bilayer oxynitride film/MgO is placed in the cavity for a "loaded" measurement. The changes of resonance frequency and quality factor thus induced allow extracting the complex permittivity of the dielectric film, further the dielectric losses. Main error source comes from the difference of dimensions and/or dielectric properties between the $\mathrm{MgO}$ substrate for the "unloaded" measurement and the $\mathrm{MgO}$ substrate on which the dielectric film is actually deposited. To get around this problem, we deposited the oxynitride dielectric film on half of a 20-mm long substrate (as shown in Supplementary data 2). This ensures that the two parts of the $\mathrm{MgO}$ substrate have undergone the same deposition process, particularly the heating at $\mathrm{Ts}=750^{\circ} \mathrm{C}$.

\section{Results and Discussion}

The characteristics of the studied films are detailed in Table 1.

\subsection{Structure of SLTTON films}

The UV-visible transmittance spectrum of the twin film deposited on $\mathrm{MgO}$ substrate in the same run than the SLTTON-1600nm sample is shown in Figure 1, with, in insert, the extrapolation giving the band gap value $(\mathrm{Eg}=2.35 \mathrm{eV})$. The fringes above the absorption threshold are related to interferences created at the air/film and film/substrate interfaces and depend on the thickness, roughness and density of film. Here, the fringes are tightened because of the high thickness $(1600 \mathrm{~nm})$ of the sample. Band gap values of other films are given in Table 1 and are around the average value $\mathrm{E}_{\mathrm{g}} \sim 2.30 \mathrm{eV}$. This is very similar to the reported values on the closest oxynitride material, $\mathrm{SrTaO}_{2} \mathrm{~N}$, with, for example, $\mathrm{E}_{\mathrm{g}}=2.27 \mathrm{eV}$ for films [7] and $\mathrm{E}_{\mathrm{g}}=2.30 \mathrm{eV}$ for bulk [10]. 
The films of the first series are phase pure according to XRD, with peaks indexed as an oxynitride isotype to $\mathrm{SrTaO}_{2} \mathrm{~N}$ (Figure 2, with the indexation of peaks made considering a pseudo-cubic cell). The $\mathrm{Nb}-(001) \mathrm{SrTiO}_{3}$ single-crystalline substrate has been chosen because of its low crystallographic mismatch with $\mathrm{SrTaO}_{2} \mathrm{~N}(+3.44 \%)$ suitable for a textured or epitaxial growth of deposited films. XRD analysis show that the films of the first series are

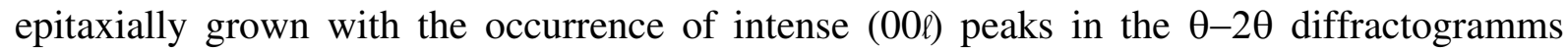
(Figure 2) and a four-fold symmetry of peaks in $\varphi$-scans (for example, for SLTTON-1600nm in Supplementary Data 3) confirming the cube-on-cube growth of the oxynitride compound on the substrate.

Cell parameters were extracted from the $\theta-2 \theta$ patterns recorded at $\chi=0^{\circ}$ (out-of-plane $c$ parameter) and $\chi=45^{\circ}$ (in-plane $a$ parameter) and the ratio $c / a$ was calculated. Ratios $c / a$ of the thick films (1600 and $300 \mathrm{~nm}$ ) are similar (respectively, 1.000 and 1.002) and close to the reported value for the $\mathrm{SrTaO}_{2} \mathrm{~N}$ bulk material ( $c / a_{\text {bulk }} \sim 1.002$ [10]). Ratio is clearly expanded for the thin SLTTON-20nm sample with a value $c / a=1.008$. It means that the latter is strained, with an elongation of the $c$ parameter in the direction of growth $(c=4.088 \AA / c$ bulk $=$ $4.039 \AA)$ and a (slight) tensile strain of the film in its plane $(a=4.054 \AA$ / $a$ bulk $=4.0306 \AA)$.

AFM images of films of the first series are presented in Figure 3. We observe a nanostructured surface for each film, with an average grain size ranging from 30 to $100 \mathrm{~nm}$ for the two thinnest films and from 10 to $70 \mathrm{~nm}$ for the thicker one. The root mean square roughness for a $10 \times 10 \mu \mathrm{m}^{2}$ scan area was measured to be around $1.5 \mathrm{~nm}$ for the $20 \mathrm{~nm}$-thin film and $3.6 \mathrm{~nm}$ for the two thicker films. The surface morphology of SLTTON-1600nm consists in dense circular grains while the thinnest films present irregular shapes. The white grains of SLTTON-20nm are actually indicative of a more pronounced peak to valley roughness of this sample; porosities are also visible. 
The films of the second series, deposited on $\mathrm{MgO}$, are phase pure and identified as an

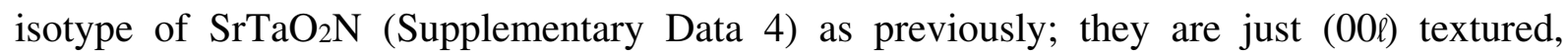
certainly due to the higher mismatch between SLTTON and this substrate (- $4.07 \%)$ compared to the $\mathrm{Nb}_{-} \mathrm{SrTiO}_{3}$ substrate $(+3.44 \%)$. As their thick homologs on the latter substrate, their ratios c/a (1.000) are close to the reported value for bulk, demonstrating fully relaxed films in accordance with their high thickness $(1520 \mathrm{~nm})$.

\subsection{Piezo-force microscopy characterization}

Figure 4 presents local remnant piezoresponse loops measured over the surface of the films deposited onto $\mathrm{Nb}$-doped $\mathrm{SrTiO}_{3}$ substrates. Regardless the films thickness, both inphase and in-amplitude PFM loops are obtained. Indeed, phase loops display a square hysteretic behavior where two stable polarization states separated of about $180^{\circ}$ are acquired, which reveal the local switching of the probed domains. From amplitude signals, typical butterfly-shape is observed traducing piezoelectric activity under the AFM tip. Besides, an asymmetry in the tip vibration-amplitude along the vertical axis is seen. This can be explained by the different work functions of the probing tip (Ti/Ir) and the conductive substrate $(\mathrm{Nb}$ $\mathrm{SrTiO}_{3}$ ), leading to an internal bias field [24]. In addition, we also note a shift toward negative voltage values along the DC bias axis, which can be related to an imprint behavior of the local switching [25, 26] consistent with the presence of an internal built-in electric field [27]. Consequently, from these local experiments, both switching behavior and electromechanical response evidence the local piezo-/ferroelectric nature of the oxynitride SLTTON thin films, as recently demonstrated by D. Oka et al [7].

\section{III.3. Low frequency dielectric characterization}


Figure 5 presents the evolution as function of the frequency from $100 \mathrm{~Hz}$ to $100 \mathrm{kHz}$ of the permittivity $\kappa$ and the dielectric losses $\tan \delta$ of the films of the first series with different thickness deposited on $\mathrm{Nb}-\mathrm{SrTiO}_{3}$ substrates. One can see a different behavior of the thicker film (SLTTON-1600nm) compared to the other two. SLTTON-20nm and SLTTON-300nm exhibit an extremely low decay of $\kappa$ and $\tan \delta$ as frequency increases, with permittivities equal to 30 and 55 at $10 \mathrm{kHz}$, respectively. The low permittivity of the SLTTON-20nm sample may be related to defaults located at the interface substrate/film, emphasized in the dielectric response of the sample due to its very low thickness. SLTTON-1600nm shows an abrupt decrease of $\kappa$ in very low frequencies, from 100 to $1500 \mathrm{~Hz}$ (the logarithm scale allows to see this decrease but enhances it disproportionately regarding the whole frequency range). This is due to the existence of space-charge regions in which free carriers are diffusing; these entities may be related to nitrogen species. The permittivity of SLTTON-1600nm becomes nearly constant above $1500 \mathrm{~Hz}$; at $10 \mathrm{kHz}, \kappa=175$. Dielectric losses tan $\delta$ reach a stable value around 0.0075 above $20 \mathrm{kHz}$. This very thick film thus exhibit better dielectric characteristics (higher $\kappa$ and lower $\tan \delta$ ) than the thinnest of the series. Indeed, this sample exhibits unique features: a band gap $(2.35 \mathrm{eV})$ characteristic of the formation of a perovskite oxynitride, a textured growth with a c-axis orientation and a very smooth surface in view of its very high thickness. The evolution of $\kappa$ and tan $\delta$ with frequency however restricts its use in the upper range of low frequencies.

At $100 \mathrm{kHz}$, the permittivity $(\kappa=175)$ of the SLTTON-1600nm film is higher than that obtained on an oxide perovskite $\mathrm{Sr}_{2} \mathrm{Ta}_{2} \mathrm{O}_{7}$ film $(\kappa=95)$, polycrystalline and deposited by sol-gel route [28]. This feature has always been evidenced for perovskite oxynitride materials compounds compared to their oxide parents, in the form of bulk [4] as well as thin films [11]. It is besides what has developed the strong enthusiasm for the perovskite oxynitride materials. 
However, it is for us to recognize that the values achieved in the present study do not reach the values observed on $\mathrm{SrTaO}_{2} \mathrm{~N}$ compound: $\kappa=750$ for bulk [10] and $\kappa=2000$ for film [7] (@10 kHz, RT). In the latter study, the high permittivity was explained by the high compressive strain attained in the film sample due to its epitaxial (001) growth on the $\mathrm{Nb}$ (001) $\mathrm{SrTiO}_{3}$ substrate. It was proposed an ordering of the nitrogen atoms along the $c$-axis of the perovskite cell, hereafter identified as a trans-type ordering. Classical type ferroelectricity was assigned to this structuration and held responsible for the observed high permittivity. This compressive strain was associated to very high ratios $c / a$, for example $c / a=1.026$ for a 20nm-thin film. In our case, we have determined a ratio $c / a=1.008$ for the SLTTON-20nm sample, which denotes a moderate strain. It is certainly too low to impact significantly the anion ordering and so, the dielectric properties. Nevertheless, the permittivity obtained here for the thickest film $(\kappa=175)$ may be related to the value obtained on bulk $\mathrm{SrTaO}_{2} \mathrm{~N}$ material ( $\kappa=750[10])$ considering that permittivities of films are generally lowered compared to bulk due to smaller grain sizes [29]. It is besides very close to the value $\kappa=200$ (@100 kHz, RT) obtained on an epitaxial $\mathrm{BaTaO}_{2} \mathrm{~N}$ film deposited by laser ablation [30].

Figure 6 presents the evolution of the permittivity and dielectric losses of the above samples as function of an applied dc electric field. No variation of the permittivity is seen, which significates no agility of these oxynitride samples at a macroscopic scale. The maximum applied fields are $600 \mathrm{kV} / \mathrm{cm}$ (not seen on the graph for clarity reason), $31 \mathrm{kV} / \mathrm{cm}$ and $62 \mathrm{kV} / \mathrm{cm}$, respectively for the SLTTON-20nm, $-300 \mathrm{~nm}$ and $-1600 \mathrm{~nm}$ samples. The first value is very high and emphasizes a more insulating character of the very thin film compared to the others. This sample has also a lower permittivity $(\kappa=30)$. So, despite a band gap value of $2.05 \mathrm{eV}$, we suggest that this sample actually contains an insulating oxide contribution which may come from the diffusion of oxygen atoms from the $\mathrm{SrTiO}_{3}$ substrate at the high temperature used during deposition $\left(\mathrm{T}_{\mathrm{S}}=750^{\circ} \mathrm{C}\right)$ [31]. Concerning its losses, they experience 
an increase in positive applied electric fields, due to the difference of nature of the top (silver) and bottom ( $\mathrm{Nb}-\mathrm{SrTiO}_{3}$ substrate) electrodes of the MIM structure. The maximum applied fields of $31 \mathrm{kV}$ and $62 \mathrm{kV} / \mathrm{cm}$ for thicker oxynitride films are lower than those currently obtained on dielectric and/or ferroelectric perovskite oxide films (for example, [32]). As already reported for bulk [4,33] and thin films [11], oxynitride materials are intrinsically more conductive than their oxide parents. This is in connection with the band-gap of oxynitrides, lower than the oxides because of the substitution of nitrogen for oxygen, thus allowing more easily the electrons to move to the conduction band. This will in turn increase the conductivity of the material, hereafter the maximum applied electric fields and the dielectric losses. Finally, since the samples do no exhibit a variation of their permittivity as function of an electric bias, no macroscopic ferroelectric polarization measurements (P-E) have been initiated.

\subsection{High frequency dielectric characterization}

Figure 7 presents the evolution as function of frequency up to $20 \mathrm{GHz}$ of the permittivity and loss tangent of the SLTTON-Hf1 sample deposited on MgO. Permittivity is stable above $5 \mathrm{GHz}$, with a value $\kappa \sim 65$ at $6.72 \mathrm{GHz}$; dielectric losses are less than 0.2 on the entire frequency range. An increase of the permittivity is seen for the lowest frequencies; this is in accordance with the value $\kappa=175$ measured via MIM structures on the SLTTON1600nm film, with thickness similar to that of SLTTON-Hf1.

The uncertainty on the $\tan \delta$ value led us to complete our measurements by using a resonant cavity on a similar $1520 \mathrm{~nm}$ thick film (SLTTON-Hf2). Supplementary Data 2 
presents the amplitude of the transmission parameters of the cavity loaded with a single $\mathrm{MgO}$ substrate and with the SLTTON-Hf2/MgO bilayer. The cavity loaded with the $\mathrm{MgO}$ substrate showed a resonance frequency of $6.7207 \mathrm{GHz}$ and a quality factor of 4019 . When the bilayer is inserted, both resonance frequency $\left(f_{r}=6.7167 \mathrm{GHz}\right)$ and quality factor $(Q=3786)$ are lowered. The application of the low perturbation analysis led to dielectric losses $\tan \delta=1.2 .10^{-}$ ${ }^{2}$. These are low, which definitively validates the use of the resonant cavity method especially adapted for low loss materials and thin films. We should add that, in transmission lines and resonant cavity methods, the tangential dielectric response of samples is only considered, so that these two methods can act as complementary characterization techniques in high frequencies.

\section{Conclusion}

(Sro.99La0.01)(Ta0.99Ti0.01) $\mathrm{O}_{2} \mathrm{~N}$ films have been successfully deposited by radio frequency magnetron sputtering using an oxide target. The use of a $93.3 \%$ vol. Ar and $7.7 \%$ vol. $\mathrm{N}_{2}$ reactive plasma allowed synthesizing oxynitride films with band gap values around 2.30 eV. Films were epitaxially grown on $\mathrm{Nb}-(001) \mathrm{SrTiO}_{3}$ substrates and textured with a preferential $c$-axis orientation on $(001) \mathrm{MgO}$ substrates. The difference in structural arrangement is due to a lower crystallographic mismatch in the case of the $\mathrm{SrTiO}_{3}$ substrate than in the case of $\mathrm{MgO}$. A series of films with thickness from 20 to $1600 \mathrm{~nm}$ reveals very smooth surfaces with root mean square roughness less than $3.6 \mathrm{~nm}$. Piezo-force microscopy demonstrated the local piezoelectric and ferroelectric behavior of the oxynitride perovskite films with the occurrence of butterfly shapes in the piezoelectric response and hysteresis curves in the ferroelectric response. The butterfly shape was not evidenced at a macroscopic scale in capacitance - electric field measurements (@10 kHz,RT). The thicker sample (1600 $\mathrm{nm}$ ) exhibits a permittivity around 175 with losses $\tan \delta=0.015$. The evolution of its 
permittivity is stable above $1500 \mathrm{~Hz}$, with, below, an increase of the permittivity related to the existence of space charge regions. The thin sample $(20 \mathrm{~nm})$ experiences a moderate crystallographic strain but does not exhibits a particular high permittivity. In high frequencies, at $6.72 \mathrm{GHz}$, the permittivity of a $1520 \mathrm{~nm}$-thick oxynitride films is around 65, with dielectric losses of 0.012 .

\section{Acknowledgments}

Authors gratefully acknowledge S. Jacq for scientific and technical assistance. This work was supported by the Syndicat de Gestion du Pôle Universitaire de Saint Brieuc and Saint Brieuc Agglomération (France). The "Région Nord-Pas de Calais" and the "Fonds Européen de Développement Régional (FEDER)" under the "Contrat de Plan État-Région (CPER)" project "Chemistry and Materials for a Sustainable Growth" are also gratefully acknowledged for funding of MFP-3D microscope.

\section{References}

[1] M. Jansen, H. P. Letschert, Inorganic yellow-red pigments without toxic metals, Nature 404 (2000) 980-982.

[2] R. Aguiar, D. Logvinovich, A. Weidenkaff, A. Rachel, A. Reller, S.G. Ebbinghaus, The vast colour spectrum of ternary metal oxynitride pigments, Dyes and Pigments 76 (2008) 70-75.

[3] K. Maeda, (Oxy)nitrides with d0-electronic configuration as photocatalysts and photoanodes that operate under a wide range of visible light for overall water splitting, Phys. Chem. Chem. Phys. 15 (2013) 10537-10548. 
[4] Y. I. Kim, P.M. Woodward, K.Z. Baba-Kishi, C.W. Tai, Characterization of the structural, optical, and dielectric properties of oxynitride perovskites $\mathrm{AMO}_{2} \mathrm{~N}(\mathrm{~A}=\mathrm{Ba}, \mathrm{Sr}$, $\mathrm{Ca} ; \mathrm{M}=\mathrm{Ta}, \mathrm{Nb}$ ), Chem. Mater. 16 (2004) 1267-1276.

[5] Y-R Zhang, T. Motohashi, Y. Masubuchi, S. Kikkawa, Sintering and dielectric properties of perovskite $\mathrm{SrTaO}_{2} \mathrm{~N}$ ceramics, J. Eur. Ceram.Soc. 32 (2012) 1269-1274.

[6] S-K. Sun, Y-R. Zhang, Y. Masubuchi, T. Motohashi, S. Kikkawa, Additive sintering, post-annealing and dielectric properties of $\mathrm{SrTaO}_{2} \mathrm{~N}$, J. Am. Ceram. Soc. 97 (2014) 10231027.

[7] D. Oka,Y. Hirose, H. Kamisaka, T. Fukumura, K. Sasa, S. Ishii, H. Matsuzaki, Y. Sato, Y. Ikuhara, T. Hasegawa, Possible ferroelectricity in perovskite oxynitride $\mathrm{SrTaO}_{2} \mathrm{~N}$ epitaxial thin films, Sci. Rep. 4 (2014) 4987.

[8] M. Yang, J. Oro'-Sole', J. A. Rodgers, A. Belen Jorge, A. Fuertes, J. P. Attfield, Anion order in perovskite oxynitrides, Nature Chem. 3 (2011) 47-52.

[9] Y-R Zhang, T. Motohashi, Y. Masubuchi, S. Kikkawa, Local anionic ordering and anisotropic displacement in dielectric perovskite $\mathrm{SrTaO}_{2} \mathrm{~N}$, J. Ceram. Soc. Japan 119 (2011) 581-586.

[10] S. Kikkawa, S. Sun, Y. Masubuchi, Y. Nagamine, T. Shibahara, Ferroelectric response induced in cis-type anion ordered $\mathrm{SrTaO}_{2} \mathrm{~N}$ oxynitride perovskite, Chem. Mater. 28 (2016) 1312-1317.

[11] Y. I. Kim, W. Si, P. M. Woodward, E. Sutter, S. Park, T. Vogt, Epitaxial thin-film deposition and dielectric properties of the perovskite oxynitride $\mathrm{BaTaO}_{2} \mathrm{~N}$, Chem. Mater. 19 (2007) 618-623.

[12] I. Marozau, A. Shkabko, M. Döbeli, T. Lippert, M. Mallepell, C. W. Schneider, A. Weidenkaff, A. Wokaun, Pulsed laser deposition and characterisation of perovskite-type $\mathrm{LaTiO}_{3 \times} \mathrm{N}_{\mathrm{x}}$ thin films, Acta Mater. 59 (2011) 7145-7154.

[13] C. Le Paven-Thivet, L. Le Gendre, J. Le Castrec, F. Cheviré, F. Tessier, J. Pinel, Oxynitride perovskite $\mathrm{LaTiO}_{x} \mathrm{~N}_{\mathrm{y}}$ thin films deposited by reactive sputtering, Progr. Solid State Chem. 35 (2007) 299-308. 
[14] Y. Lu, C. Le Paven, H. T. Nguyen, R. Benzerga, L. Le Gendre, S. Rioual, F. Tessier, F. Cheviré, A. Sharaiha, C.Delaveaud, X. Castel, Reactive sputtering deposition of perovskite oxide and oxynitride lanthanum titanium films: structural and dielectric characterization, Crystal Growth and Design 13 (2013) 4852-4858.

[15] C. Le Paven, L. Le Gendre, R. Benzerga, F. Cheviré, F. Tessier, S. Jacq, S. TraoréMantion, A. Sharaiha, Growth of (Sr,La)-(Ta,Ti)-O-N perovskite oxide and oxynitride films by radio frequency magnetron sputtering: Influence of the reactive atmosphere on the film structure, J. Cryst. Growth 413 (2015) 5-11.

[16] S. Nanamatsu, M. Kimura, K. Doi, S.Matsushita, N. Yamada, A new ferroelectric: $\mathrm{La}_{2} \mathrm{Ti}_{2} \mathrm{O}_{7}$, Ferroelectrics 8 (1974) 511-513.

[17] H. Yan, H. Ning, Y. Kan, P. Wang, M.J. Reece, Piezoelectric ceramics with superhigh Curie points, J. Am. Ceram. Soc. 92 (2009) 2270-2275.

[18] S. Jacq, C. Le Paven, L. Le Gendre, R. Benzerga, F. Cheviré, F. Tessier, A. Sharaiha, Deposition and dielectric characterization of strontium and tantalum-based oxide and oxynitride perovskite thin films, Solid State Sci. 54 (2015) 22-29.

[19] D. Kubelka, L. Munk, Ein beitrag zur optik der farbanstriche, Z. Tech. Phys. 12 (1931) 593-601.

[20] B. J. Rodriguez, C. Callahan, S. V. Kalinin, R. Proksch, Nanotechnology 18 (2007) 475504.

[21] E. Carlsson, S. Gevorgian, Conformal mapping of the field ans charge distributions in mulilayered substrate CPWs, Microw. Theory Tech. IEEE 47 (1999) 1544-1552.

[22] P. Queffelec, V. Laur, A. Chevalier, J-M. Le Floch, D. Passerieux, D. Cros, V. Madrangeas, A. Le Febvrier, S. Députier, M. Guilloux-Viry, G. Houzet, T. Lacrevaz, C. Bermond, B. Fléchet, Intercomparison of Permittivity Measurement Techniques for Ferroelectric Thin Layers, J. Appl. Phys. 115 (2014) 024103.

[23] V. Laur, P. Queffelec, Cavity-perturbation method improvement by a numerical calibration process, Microwave Opt. Technol. Lett. 56 (2014) 904-906. 
[24] J. Hong, H. W. Song, S. Hong, H. Shin, K. No, Fabrication and investigation of ultrathin, and smooth $\mathrm{Pb}(\mathrm{Zr}, \mathrm{Ti}) \mathrm{O}_{3}$ films for miniaturization of microelectronic devices, J. Appl. Phys. 92 (2002) 7434-7441.

[25] A. Gruverman, A. Kholkin, A. Kingon, H. Tokumoto, Asymmetric nanoscale switching in ferroelectric thin films by scanning force microscopy, Appl. Phys. Lett. 78 (2001) $2751-2753$.

[26] A. Ferri, S. Saitzek, A. Da Costa, R. Desfeux, G. Leclerc, R. Bouregba, G. Poullain, Thickness dependence of the nanoscale piezoelectric properties measured by piezoresponse force microscopy on (111)-oriented PLZT 10/40/60 thin film, Surf. Sci. 602 (2008) 1987-1992.

[27] C. Lichtensteiger, S. Fernandez-Pena, C. Weymann, P. Zubko, J.-M. Triscone, Tuning of the depolarization field and nanodomain structure in ferroelectric thin films, Nano Lett. 14 (2014) 4205-4211.

[28] K. Kato, Surface morphology and dielectric properties of alkoxy-derived $\mathrm{Sr}_{2} \mathrm{Ta}_{2} \mathrm{O}_{7}$ and $\mathrm{Sr}_{2}(\mathrm{Ta}, \mathrm{Nb})_{2} \mathrm{O}_{7}$ thin films, J. Mater. Sci. Mater. Electr. 11 (2000) 575-578.

[29] J. Petzelt, S. Kamba, J. Hlinka, Ferroelectric soft modes in ceramics and films, in New developments in advanced functional ceramics. Ed. L. Mitoseriu, Indian Series of Appl. Phys., Transworld Research Network 37/661, Trivandrum,.Kerala, India, pp. 387-421 (2007).

[30] Y. I. Kim, W. Si, P. M. Woodward, E. Sutter, S. Park, T. Vogt, Epitaxial thin-film deposition and dielectric properties of the perovskite oxynitride $\mathrm{BaTaO}_{2} \mathrm{~N}$, Chem. Mater. 19 (2007) 618-623.

[31] C.W. Schneider, M. Esposito, I. Marozau, K. Conder, M. Doebeli, Y. Hi, M. Mallepell, A. Wokaun, T. Lippert, The origin of oxygen in oxide thin films: role of the substrate, Appl. Phys. Lett. 97 (2010) 192107.

[32] Y. Corredores, A. Le Febvrier, X. Castel, R. Sauleau, R. Benzerga, S. Députier, M. Guilloux-Viry, A. Mekadmini, N. Martin, G. Tanné, Study of ferroelectric/dielectric multilayers for tunable stub resonator applications at microwaves, Thin Solid Films 553 (2014) 109-113. 
[33] S. G. Ebbinghaus, H.-P. Abicht, R. Dronskowski, T. Muller, A. Reller, A. Weidenkaff, Perovskite-related oxynitrides - Recent developments in synthesis, characterization, and investigations of physical properties, Prog. Solid State Chem. 37 (2009) 173-205. 


\section{List of Figure captions}

Figure 1. UV-visible transmittance spectrum of the twin film (orange in color, deposited on $\mathrm{MgO}$ substrate) of the SLTTON-1600nm sample. The extrapolation, giving the band gap, is shown in insert.

Figure 2. $\theta-2 \theta$ diffractogramms of SLTTON films deposited on $\mathrm{Nb}-(001) \mathrm{SrTiO}_{3}$ substrates by reactive sputtering with different thickness. Indexation is made according to a pseudocubic cell of SLTTON, with (Ag) related to the metallization for MIM measurements, $(\bullet)$ to the substrate and $(*)$ to the sample holder.

Figure 3. AFM surface morphology of the (a) 20-, (b) 300- and 1600-nm-thick SLTTON films.

Figure 4. Nanoscale piezo-/ferroelectric response of the SLTTON films. Local phase and amplitude piezoresponse loops measured over the surface of the films with thickness of (a) 20, (b) 300 and (c) $1600 \mathrm{~nm}$.

Figure 5. Evolution as function of the frequency of: (a) permittivity $\kappa$ and (b) dielectric losses $\tan \delta$ of SLTTON films with different thickness deposited on $\mathrm{Nb}_{-} \mathrm{SrTiO}_{3}$ substrates by reactive sputtering.

Figure 6. Evolution as function of an applied dc electric field of: (a) permittivity ( $\kappa$ ) and (b) loss tangent $(\tan \delta)$ of SLTTON films with different thickness deposited on $\mathrm{Nb}-\mathrm{SrTiO}_{3}$ substrates by reactive sputtering.

Figure 7. Evolution as function of frequency of: (a) permittivity and (b) loss tangent of the SLTTON-hf1 film deposited on $\mathrm{MgO}$ substrate by reactive sputtering. 
Figure 1.

Small column size: $90 \mathrm{~mm}$ width

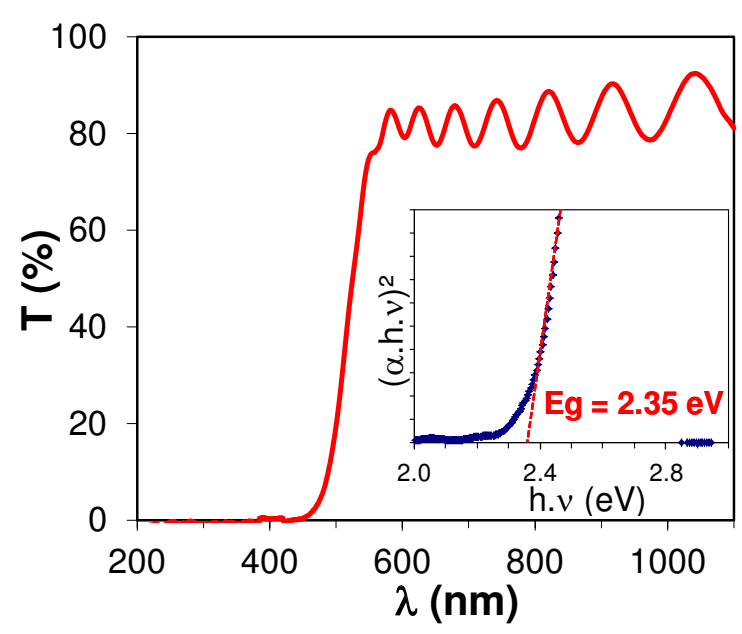

One and a half page width: $140 \mathrm{~mm}$ width

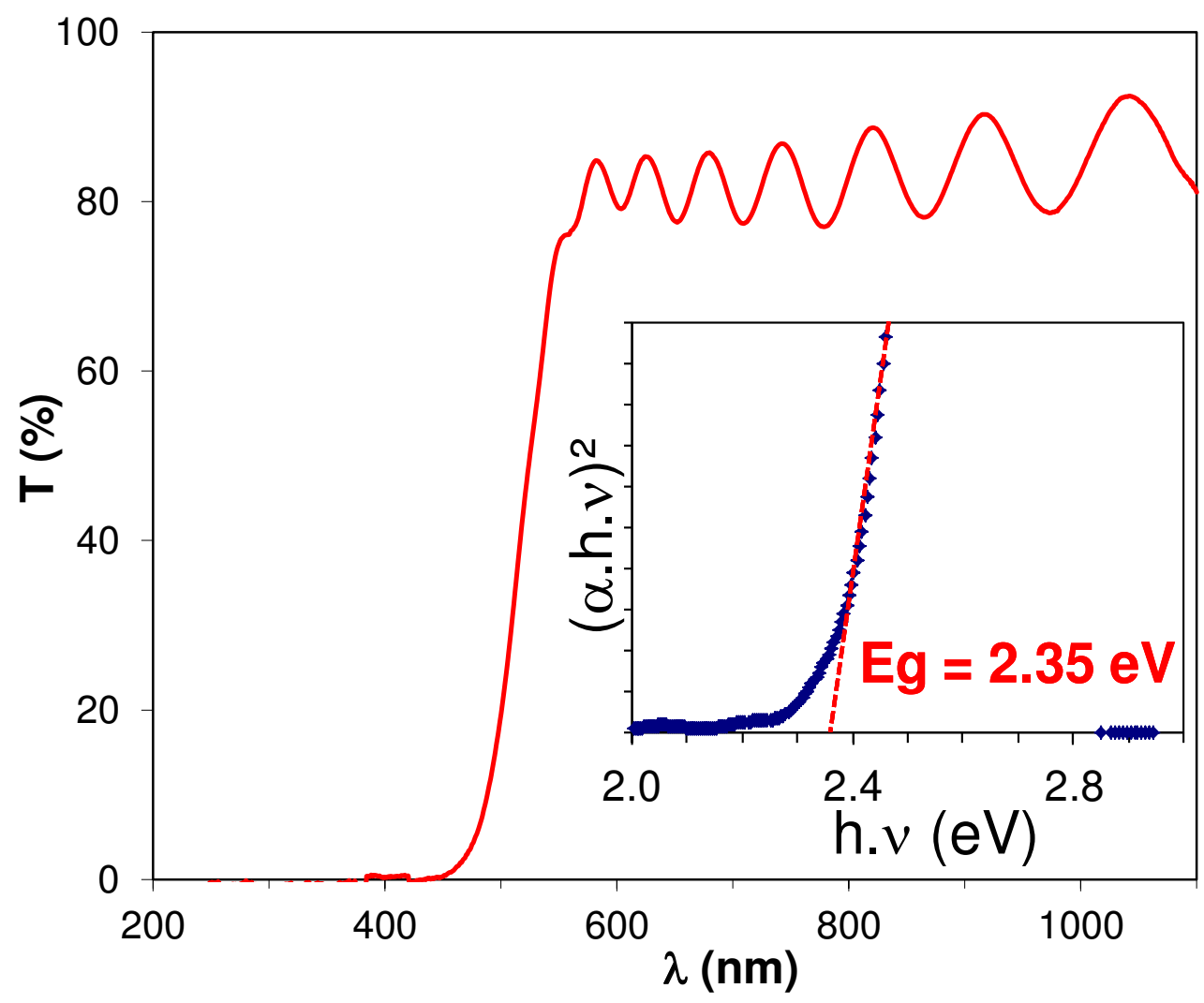


Figure 2.

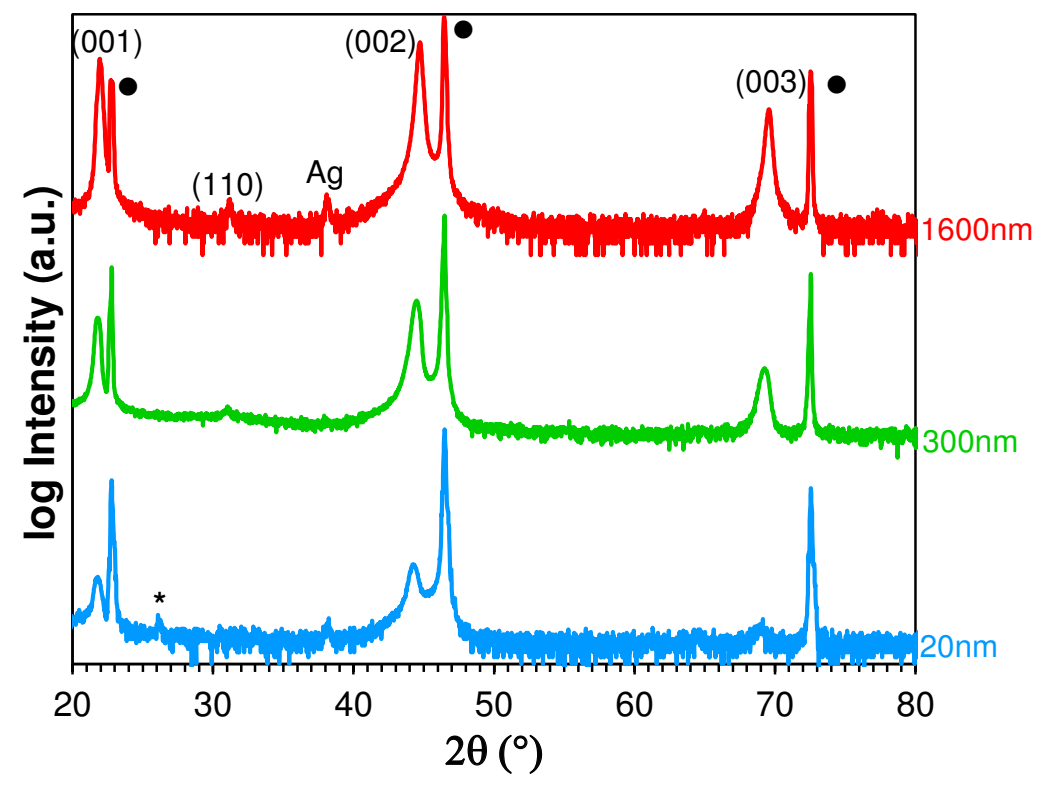


Figure 3.
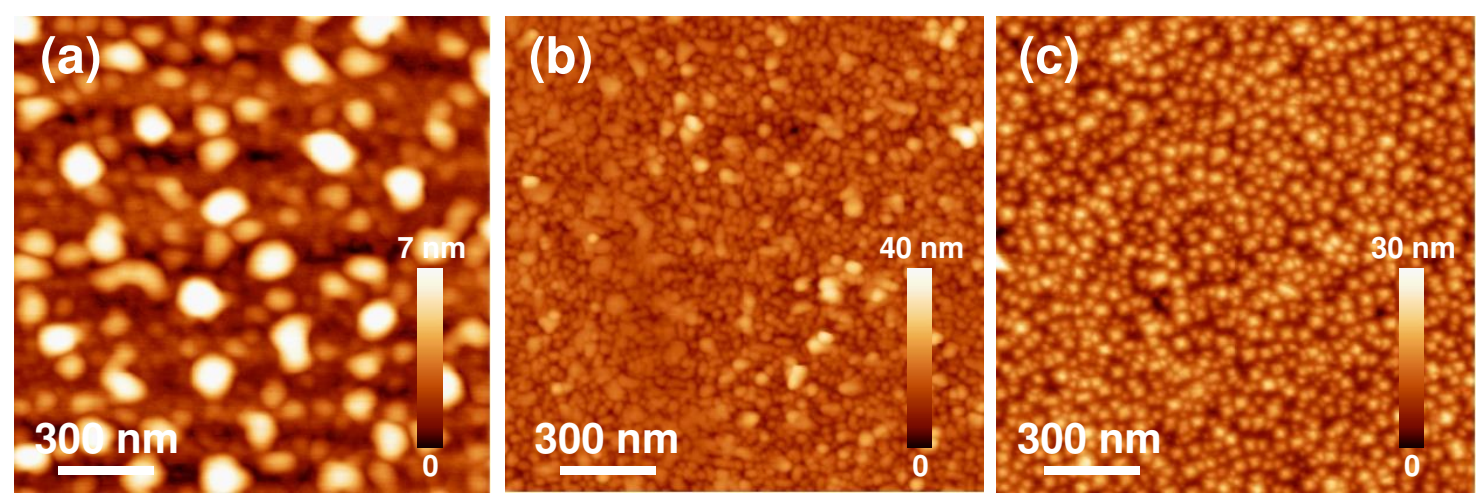
Figure 4.
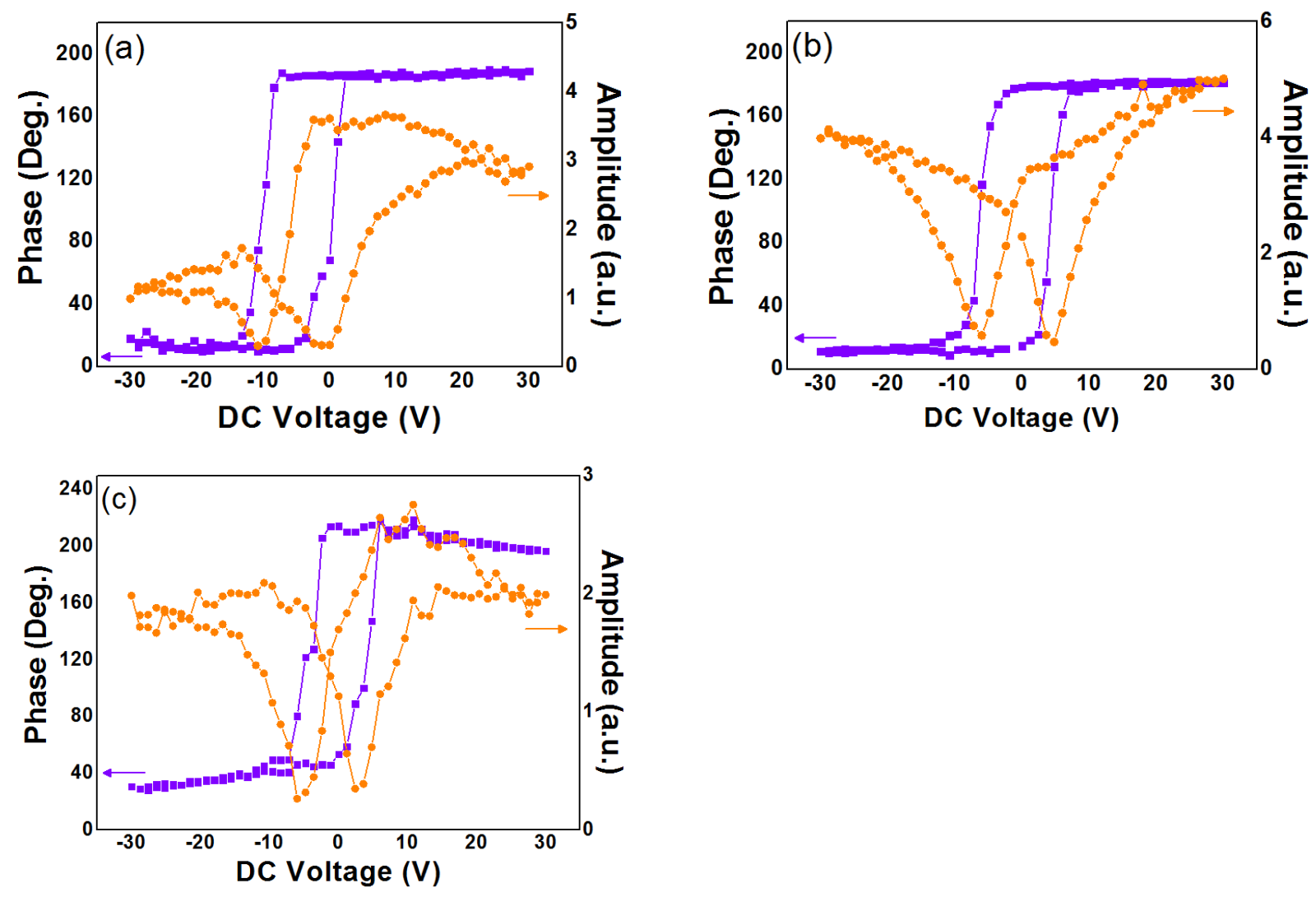
Figure 5.
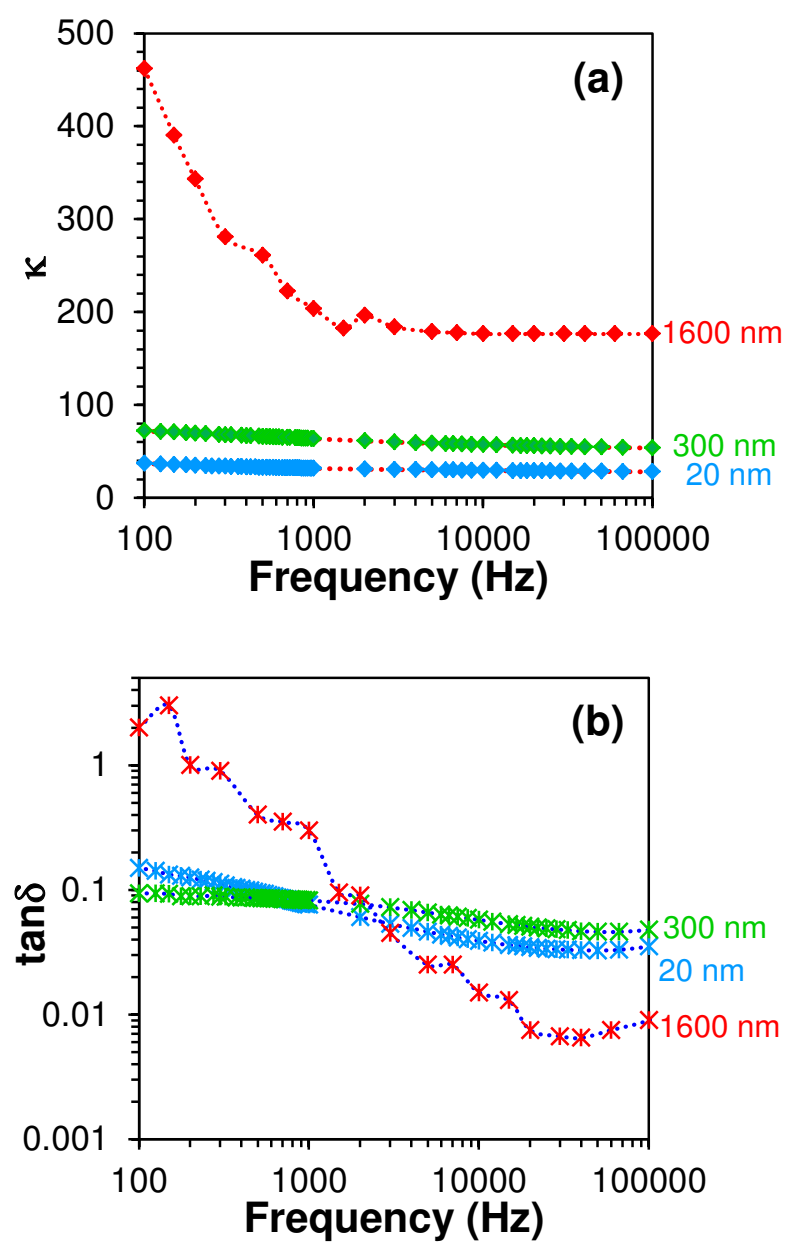
Figure 6.
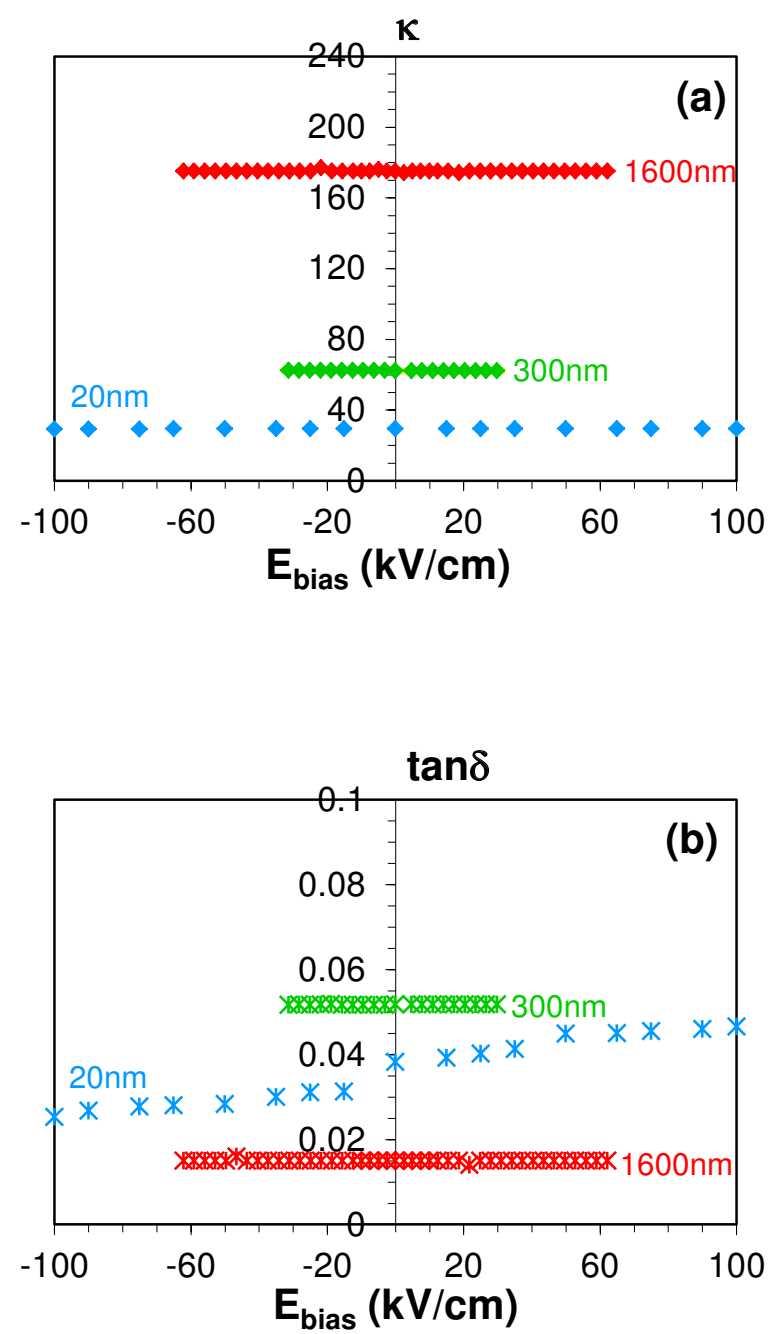
Figure 7.
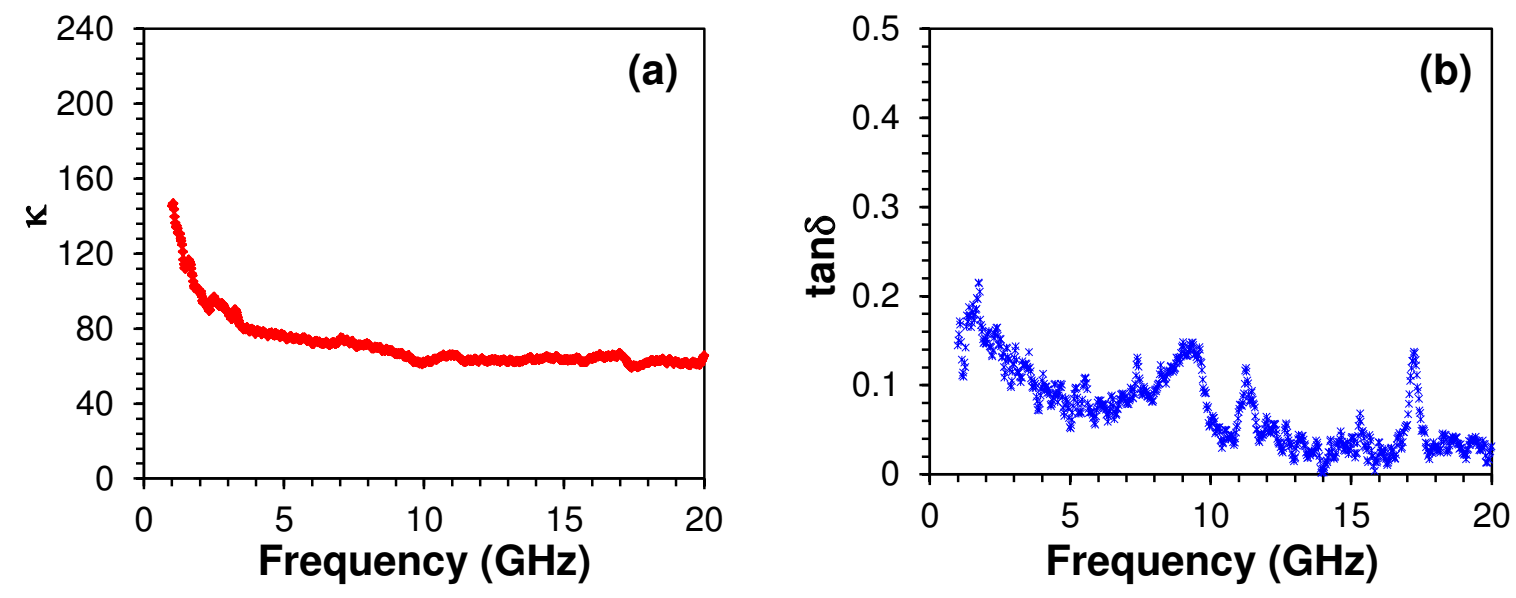